\title{
HIGH THERMOELECTRIC PERFORMANCE OF p-BiSbTe COMPOUNDS PREPARED BY ULTRA-FAST THERMALLY INDUCED REACTION
}

\author{
X. Su*a, Y. Yan ${ }^{a}$, and X. Tang ${ }^{a}$ \\ a State Key Laboratory of Advanced Technology for Materials Synthesis and Processing, \\ Wuhan University of Technology, Wuhan, 430070 China \\ *e-mail: suxianli@whut.edu.cn
}

DOI: 10.24411/9999-0014A-2019-10169

The traditional zone melting $(\mathrm{ZM})$ method for the fabrication of state of the art $\mathrm{Bi}_{2} \mathrm{Te}_{3}$-based thermoelectric materials has long been considered a time and energy intensive process. Herein, a combustion synthesis known as the thermally induced flash synthesis (TIFS) is employed to synthesize high performance p-type BiSbTe alloys within 20 min compared to tens of hours for the ZM samples. The thermodynamic parameters and phase transformation mechanism during the TIFS process were systematically studied for the first time. TIFS combined with plasma activated sintering (PAS) results in a single-phase homogeneous material with excellent repeatability, high thermoelectric performance (maximum $Z T \sim 1.2$ at $373 \mathrm{~K}$ ) and robust mechanical properties in a very short time of less than $20 \mathrm{~min}$. The technologically relevant average $Z T$ value of TIFS-PAS fabricated $\mathrm{Bi}_{0.5} \mathrm{Sb}_{1.5} \mathrm{Te}_{3}$ from $298 \mathrm{~K}$ to $523 \mathrm{~K}$ is 0.86 , about a 46\% improvement over the ZM sample. The compressive and bending strength of TIFS-PAS $\mathrm{Bi}_{0.5} \mathrm{Sb}_{1.5} \mathrm{Te}_{3}$ are also improved by about 5 fold compared with those of the $\mathrm{ZM}$ samples. Thermoelectric power generation modules assembled using the TIFS-based high performance $\mathrm{n}$ and $\mathrm{p}$ type materials show the largest thermoelectric conversion efficiency of $5.2 \%$ when subjected to a temperature gradient of $250 \mathrm{~K}$, representing about $42 \%$ enhancement compared with the commercial ZM-based module. Because of the simplicity and scalability of the process and short synthesis time, the TIFS-PAS technology provides a new and efficient way for large-scale, economical fabrication of $\mathrm{Bi}_{2} \mathrm{Te}_{3}$-based thermoelectrics. 